NASA Technical Memorandum 108171

\title{
AN INTERNATIONAL AEROSPACE INFORMATION SYSTEM: A COOPERATIVE OPPORTUNITY
}

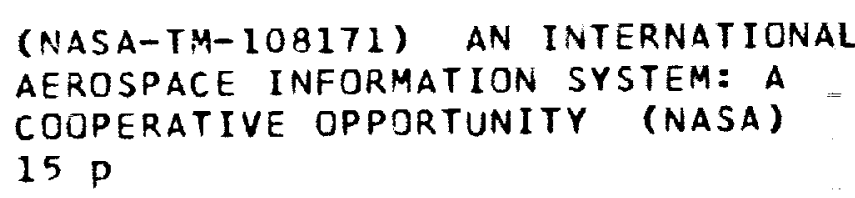
AN INTERNATIONAL N92-33237

$63 / 82 \quad 0120908$

Walter R. Blados and Gladys A. Cotter

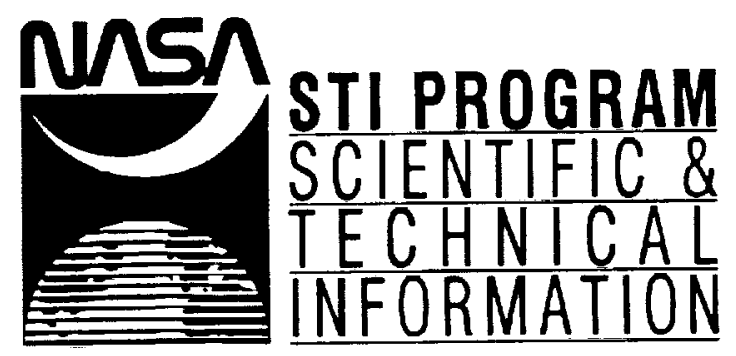


NASA Technical Memorandum 108171

\section{AN INTERNATIONAL AEROSPACE INFORMATION SYSTEM: A COOPERATIVE OPPORTUNITY}

Walter R. Blados and Gladys A. Cotter

NASA Scientific and Technical Information Program, Washington, DC 
Scientific and technical information (STI) is a valuable resource that represents the results of large investments in research and development $(R \& D)$, and the expertise of a nation. NASA and its predecessor organizations have developed and managed the preeminent aerospace information system. We see information and information systems changing and becoming more international in scope. In Europe, consistent with joint $R \& D$ programs and a view toward a united Europe, we have seen the emergence of a European Aerospace Database concept. In addition, the development of aeronautics and astronautics in individual nations has also led to initiatives for national aerospace databases. Considering recent technological developments in information science and technology, as well as the reality of scarce resources in all nations, it is time to reconsider the mutually beneficial possibilities offered by cooperation and international resource sharing. This paper raises for consideration new possibilities for unification of the various aerospace database efforts toward a cooperative insernational aerospace database initiative that can optimize the costbenefit equation for all participants.

As we near the end of the Twentieth Century, we find ourselves living in a new environment, a new age-an information society, an information age - that offers new opportunities for organizational and individual excellence. New relationships and new opportunities are emerging as a result of the increased availability of information and the stimulation and expanding opportunities it brings. There will be new individual and organizational relationships, new methods of doing our work, and new environments in which we will carry out our work.

Information is increasingly becoming a strategic resource in all societies and economies. Information is the basis on which most new jobs are being created, new wealth generated, and new productive activities started. Information is a primary determinant of the competitive position of industry in the marketplace. Information is the driving force behind the internationalization of the marketplace. In societal terms, information is of growing significance, not only in the role it plays in our economic affairs, but in the way it influences how we live and the way we function as citizens.

Information itself is also changing in character:

- There is more of it.

- It is treated increasingly like a commodity, that is, bought and sold.

- It is becoming increasingly internationalized; information sources are now global rather than national or local.

- It is becoming more transient, as a function both of the increasing speed with which new information gets produced and the rapidity of its dissemination. 
- The formats for presentation of information are changing. The traditional formats of the spoken word and print publication have been augmented by electronic data-bases, television, video, CD-ROM, etc.

- The formats for information production are being altered, mainly through the intervention of computer technologies.

Computer and communications technology is the driving force behind most of both the changing character of information itself and the strategic role that information plays in the economy and society.

Given information's strategic importance and changing characteristics, questions surrounding the collection, storage, retrieval, preservation, and use of information acquire a new imperative. At the same time, the same two factors; i.e., strategic importance and changing characteristics, make the answers to these questions far more complex and difficult than they have ever been before. This complexity and difficulty, moreover, is no longer (if it ever was) merely a question of finding a technical solution. There are now economic, political, social, and cultural dimensions to the questions that must also be factored into the search for answers.

In this new information-oriented culture, the U.S. aerospace industry, especially the commercial aviation sector, is also undergoing profound change as a result of the circumstances created by a combination of domestic actions (such as deregulation) and external trends and events (such as emerging foreign competition). The future will show an increase in U.S. collaboration with foreign producers, resulting in a more international manufacturing environment, and will foster an increasing flow of U.S. aerospace trade. Simultaneously, international industrial alliances will result in more rapid diffusion of technology, thus increasing pressure on the U.S. aerospace industry to push forward with new technological developments.

There are certain characteristics that make the aero-space industry unique: in many countries it leads all other industries in expenditures for research and development (R\&D); it benefits heavily as a technological borrower from developments in other industries such as metallurgy, materials, chemicals, and petroleum; it is characterized by the high degree of systemic complexity embodied in its products; and in the U.S., it has been the beneficiary of federally funded R\&D for nearly a century.

An integral part of the aerospace R\&D process is the scientific and technical information (STI) associated with it. STI is both a raw material (input) and a product (output) of this process. The systems that support STI are part of the scientific and technical (S\&T) infrastructure. The data or existing knowledge bases 
are a raw material necessary for the production of new findings and developments. Strong STI programs are critical to a strong national S\&T base.

Information processing in aerospace $R \& D$, as well as in defense or any other $\mathrm{R} \& \mathrm{D}$ activity, is viewed as an ongoing problem-solving cycle involving each activity within the innovation process, the larger organization, and the external world. For purposes of this paper, the innovation process is conceptualized as a process of related activities or units beginning with research on one end, and culminating with service and maintenance on the other. Figure 1 graphically portrays this process.

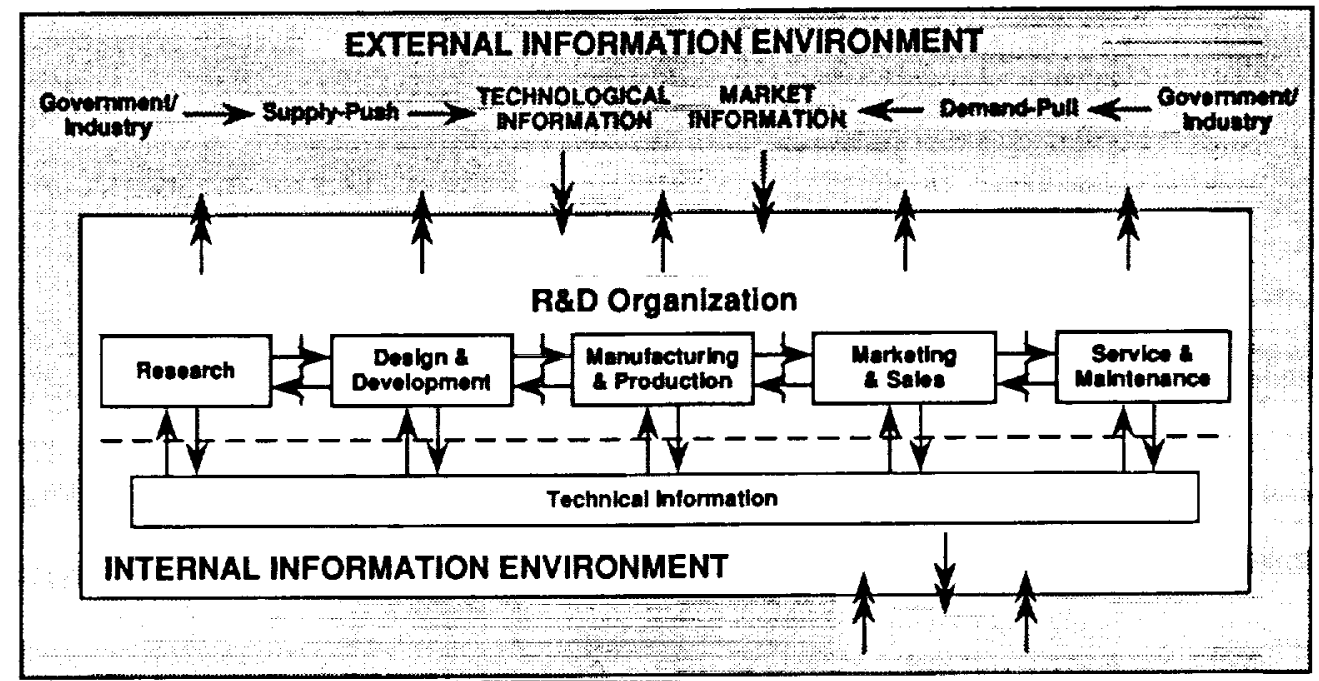

Figure 1. The Innovation Process as an Information Processing System

For any given task, each activity or unit of the innovation process must identify, gather, and assess scientific, technical, and market information from the external information world. New (external) and established (internal, inhouse) information must be effectively processed within the work area: decisions, solutions, and approaches must be developed and coordinated within each activity and within the organization; and outputs, such as decisions, processes, products, and information, must be effectively transferred to the external environment. The outputs of this process create conditions for another set of similar activities, thereby initiating another information processing cycle. Numerous studies have revealed a strong relationship between successful innovation, idea formulation, and information external to the organization.

Timely, accurate, and relevant STI is critical to the R\&D process. STI is an incredibly valuable resource that directly affects the cost of performing a technical task, the quality of the results, and productivity. Further, STI has value that may be exploited more widely than the purpose for which it was originally collected. 
It can serve as a critical link between $R \& D$ and the achievement of other national goals such as improving the education of scientists and engineers, strengthening the technology base, and fostering international cooperation on global problems. Even further, the diffusion of knowledge resulting from aerospace R\&D is indispensable in maintaining the vitality and international competitiveness of the aerospace industry.

\section{Emerging Trends}

Several emerging trends have a significant impact on the conduct of science, R\&D, and the corollary management activities. These trends dictate that issues of STI be addressed. The trends include the expanding use of information technology, the growth of interdisciplinary research, and an increase in international collaboration and development of international standards.

Information technology has a significant impact on the conduct of science and engineering efforts. It has dramatically changed the conduct of research, and has brought forth a need to better understand and manage its exploitation. Computerized instruments gather data many orders of magnitude greater than by previous methods. Telecommunication capabilities can link researchers to computing facilities with vast capabilities and with data sources not constrained by geographical location. Data are available, not only in computerized databases, but also from sensing and other data-gathering instruments. New analytical approaches to research questions are possible through graphics, color enhancement, animation, other visualization techniques, and computerized analyses of massive databases. Communications networks link scientists to each other, to distributed databases, and to remote instruments and computing resources. All of these capabilities overwhelm traditional data management techniques and create pressure to change accepted information practices. With this ever-growing capability, there is a need to teach researchers to better use it, to develop better ways to store, retrieve and maintain the integrity of data, and to determine how to assure intellectual property rights in an electronic network.

Many of the significant research challenges today are interdisciplinary, which requires expanding the circle of collaborators' and researchers' range of information sources. A network of communications links will soon develop worldwide to link personal computers, work stations, databases, peripherals, and information utilities. Information systems will become transparent, and will facilitate the flow of information and meaning among people. Consequently, we will be able to focus on content, not technology. Responsive expert advice, information, and solutions will be at our fingertips.

Notwithstanding these communications networks and large databases, the different methodologies, vocabularies, and cultures of individual disciplines create obstacles 
to efficient information exchange. Systems need to be designed to accommodate users who were not immediately involved in the original research. Merging existing data collections from different fields to perform analyses creates new problems. It becomes extremely difficult to compare data that were derived using different techniques or approaches. Contributing to this problem is the lack of standards for data exchange formats which hampers the building of these multidisciplinary databases. The bottom line is that we must be prepared to import external information to support the internal R\&D process, assure real-time delivery of information to support the transfer and transition of technology within the R\&D community, and be able to export some results to remain competitive in the R\&D arena, as well as to provide visibility to the NASA organization.

These problems are further compounded by the growing internationalization of science. STI is being produced, enhanced, and stored around the globe. Single countries in some cases are acknowledged leaders in select scientific and technical disciplines. Many major research efforts involve worldwide data collection. Not only are a variety of disciplines involved, but scientists from around the world are participating in these efforts. The users in these projects are distant geographically as well. Global economies dictate that every effort be made to reduce unnecessary product and service development cost. Communications networks facilitate the exchange of ideas and access to remote databases, but there is still much progress that needs to be made in making systems more transparent and in developing common protocols.

Hence, the pace of data collecting, the growth of international approaches to research, and the tendency to cross traditional disciplinary boundaries all cast a new perspective on earlier STI issues and raise new challenges for effectively providing critical information to the end user.

\section{The NASA Aerospace Database}

The United States was a major and early entrant into the aerospace R\&D arena through the creation of the National Advisory Committee on Aeronautics (NACA) in 1915, followed by the creation of the National Aeronautics and Space Administration (NASA) in 1958.

From the very beginning, the need for and role of a centralized scientific and technical information system was recognized. NASA's enabling legislation requires NASA to "provide for the widest practicable and appropriate dissemination of information concerning the activities and the results thereof." The international nature of the mission was also recognized for NASA to conduct its activities "so as to continue to contribute materially to...cooperation by the United States with other nations and groups of nations in work pursuant to the Act and in the peaceful application of the results thereof." 
This led to the early commitment and continued development of a NASA STI Program and a NASA Aerospace Database (NAD) consisting of worldwide information.

As the aerospace programs of other nations grew, particularly in Europe with the creation of the European Space Agency (ESA), NASA found a natural partner for cooperation in its technical and information programs. NASA expanded its database input to include resources provided by ESA.

More recently in Europe, and consistent with joint $R \& D$ programs and a view toward a United Europe, we have seen the emergence of a European Aerospace Database (EAD) concept. Today, in addition to the ESA programs, the development of aeronautics and astronautics in individual nations has also led to initiatives (in various degrees of development) of national aerospace databases such as the German Aeronautics and Astronautics Database-Deutsche Luft und Raumfahrt Datenbank (DELURA)-initiative and a Japanese aerospace database called the Japanese Aerospace Information Reference System (AIRS).

Considering the advances that have been made in information technology, the increased international participation in the aerospace field, and the realities of scarce resources for every nation, the time seems right to rethink strategies for cooperation and international resource sharing.

A vital part of this thinking involves participating in dialogues on the subject with current international exchange partners. The feedback the NASA STI Program has been receiving, including the statements made at the European Forum on Information and Documentation held in Strasbourg in January 1992 by database producers and users clearly indicate that there is a desire for international cooperation and a need for program flexibility and change.

The question now is where to go from here. This paper introduces some ideas and discusses the issues relevant to an initiative to unify international aerospace database efforts. A unified effort will result in a cooperative international aerospace database that will optimize the costbenefit equation for all participants.

The NAD currently contains $2,250,000$ research summaries covering 1962 to the present. About 27 percent of the NAD consists of R\&D results originally published outside of the U.S. This percentage is increasing; in 1990 it was 36 percent. This is a result not only of better acquisition processes, but also the fact that an increased proportion of the knowledge base is being developed abroad. Figure 2 provides a graphic breakdown of these numbers by major geographic areas. 


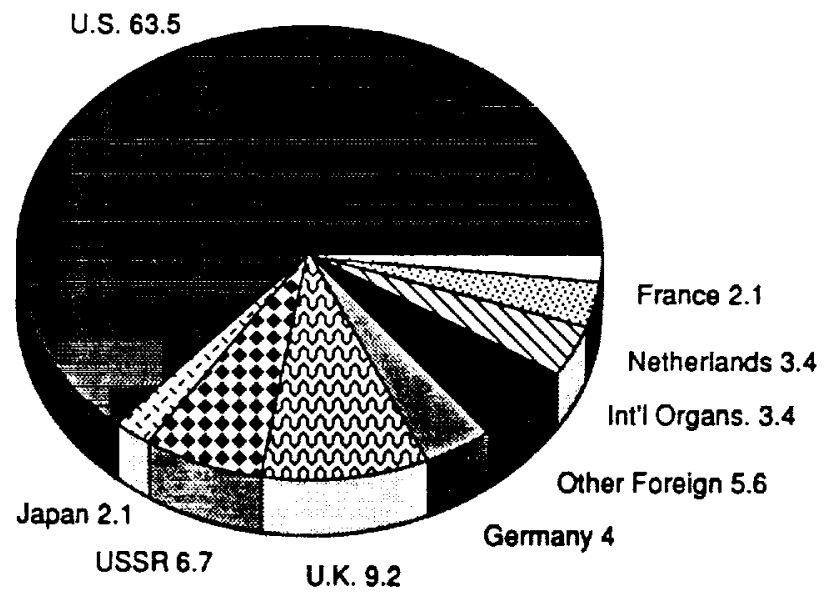

Figure 2. Percent of R\&D Summaries in the NASA Aerospace Database, by Country, for 1990 Input

Of the non-U.S. material, more than 10 percent of the original documents are written in languages other than English. The NAD has English language summaries of all of these research publications. The NAD is the premier aerospace database in the world, and has served as the de facto international aerospace database.

The NAD was created and is maintained for a single purpose-to advance knowledge by providing access to an organized repository of aerospace information. Having the "largest" or the "best" or the "easiest to use" database means nothing if the knowledge worker who utilizes the resource is not satisfied.

The NASA STI Program has been surveying its worldwide customer base to assess satisfaction levels and to determine areas in need of improvement. Responses thus far appear to have common concerns; the major concerns (along with possible solutions) of the NASA international customers appear to be

- the NAD is not complete

- $\quad$ expand subject coverage

- $\quad$ expand coverage of non-U.S. literature

- $\quad$ increase the number of items acquired each year

- $\quad$ include more types of information (numeric, factual, multimedia)

- the full text of the document is needed rapidly

- improve current system of online bibliographic citations and delivery schedule for the document

- provide customers with access to the full text from the desktop/office

- the retrieval system needs to be improved

- make system intuitive to use

- improve precision of retrieval

- a virtual database is acceptable. 
These issues all fit into the theme of supporting the decision-making process. If researchers need information to determine how to structure a project or what direction to take, they want the decision-supporting information regardless of the country of origin.

They also need access to interdisciplinary information-not just to their own specialty-and they need all the information rapidly. Improved retrieval systems that are "intuitive" to use will allow researchers to embed the information-seeking and delivery tools that we develop into their daily decision-making process.

Interestingly, the international exchange partners with whom we have held meetings on this subject expressed similar concerns. Key issues that they were concerned with include the following:

- the NAD scope and subject coverage are too limited;

- the NAD acceptance criteria for selection of documents to be included in the database is too restrictive;

- NAD access policies (who and how) are too restrictive; and

- $\quad \mathrm{NAD}$ format requirements must be rethought and reconsidered.

Change is definitely needed.

\section{Improving International Cooperation}

Hence, from the input from all the sources contacted thus far, both national and international, it is readily apparent that there is a need to change current practices. Also important is the fact that technological, economic, and policy considerations dictate that changing these practices is a necessary and desirable step to improving international cooperation in STI.

Let us first examine the technological consideration. Some of the technological barriers that have resulted in restrictive policies in the past have been removed. Storage costs have decreased tremendously, retrieval capabilities have improved, and networking solutions are widely available. It is no longer necessary to implement policies to discard potentially useful information because it is too expensive to keep in a costly centralized system or because it will "clutter" search results with irrelevant information.

More important, we in the information management and service sector are facing a potentially major paradigm shift in the way information is produced, managed, and used. There is an opportunity through international cooperation to develop a 
more unified approach to how our services can accommodate these changes that will aid all of our individual user communities.

Looking at the economic issue, we find that because of budget constraints that we are all facing, cost leveraging and sharing results are not only highly desirable, but absolutely necessary. By sharing the costs for acquiring and processing the worldwide aerospace literature, we will all benefit from having more information available for our user communities. The resulting cost savings will afford us an opportunity to commit funds for processing unique information, expanding acquisitions, adding value to our current abstracting and indexing processes, or adding new types of information such as research in progress, numeric data, or multimedia information to the exchange relationship.

Cost sharing in the area of the development and operation of our information systems themselves is another possibility. Can we share in the development of the next generation of systems? Can we share network solutions? Cooperation in information technology development will likely lead to systems solutions far more advanced and sophisticated than any that could be financially supported by a single institution.

Concerning the policy issue, there will be a need to develop new policies to reap the full benefits from the opportunities presented by the act that networks and the internationalization of science will increasingly eliminate boundaries to international information flow. Compatible policies and standards for the structure and content of aerospace databases or information will greatly add to the utility of the information that these networks can deliver.

Existing NASA STI policies and restrictive scope definitions will no longer have any positive value in this environment and will only act as disincentives to international cooperation.

\section{Recommendations for IAD Cooperation}

Although an evaluation of current reactions to the NASA Aerospace Database indicates that the NAD may be the most comprehensive international aerospace database (IAD), it is by no means complete. Our goal at NASA is to strive to establish as comprehensive and complete a database as possible; one that will satisfy the information needs of our user base. The most practical way to achieve this is to work with all the other organizations who share this goal, and to develop cooperative strategies to realize it.

As a first step in this international unification and mutual cooperation effort, an advisory group of representatives from interested organizations should be organized and established. One of the first actions that this advisory group might 
undertake is to develop a comprehensive list of IAD issues to be addressed. These issues might include examining:

- How current existing exchange relationships can form the basis for a more cooperative international effort:

- What types of agreements and relationships will encourage involvement?

- $\quad$ Should a formal group be established to set policy for an IAD?

- Can user meetings be scheduled on a regular basis?

- How to make the bibliographic database more comprehensive and timely:

- How can information producers be motivated to provide input?

- Would countries be responsible for providing their own national input?

- $\quad$ How would coverage of those parts of the world not participating in the effort be accomplished?

- How to update the scope, the thesaurus, and other standards:

- $\quad$ Should a team of experts be appointed?

- Would a survey method be appropriate?

- How to make the database available:

- Who would be eligible for access?

- What should pricing strategies be?

- What is an appropriate network architecture?

- What strategies are necessary to go beyond bibliographic cooperation into sharing of other kinds of data and information, including improvements in systems and technology for delivery and management of information?

- How to reconcile the national need for proprietary aerospace information with participation in an IAD:

- Will nations still maintain national databases?

- How can reciprocity be ensured?

- How will intellectual property rights be protected?

We suggest that this advisory group develop a temporary operating structure that could be used to test and refine the IAD concept. After a period of test and refinement, the structure would be formalized and institutionalized. 
The NASA STI Program is working with its current exchange partners such as ESA to determine if there is enough support for an IAD to set up an advisory group and move forward on this concept. Given enough interest, the effort could begin in 1993, and we would be on our way towards developing a truly international and comprehensive aerospace database.

\section{Bibliography}

1. Blados, Walter R. "Quo Vadimus? Coming to Grips With the Information World," NASA Technical Memorandum 105138, May 1991.

2. Buerk, K. "Aerospace Information in the Federal Republic of Germany," Paper presented at the Strasbourg Conference on Information Documentation, January 17-19, 1990 and published in Proceedings: Information-Documentation: European Forum, Strasbourg, France, January 1990, by Association Aeronautique et Astronautique de France, Paris, 1990, pps. 9-17.

3. Cotter, G. and T. Lahr, "Unification: An International Aerospace Issue," paper presented at the 30th Aerospace Sciences Meeting and Exhibit, January 6-9, 1991 and published by the American Institute of Aeronautics and Astronautics, Washington, DC, 1991.

4. Cotter, G., T. Lahr, and B. Cooper, "Unification: An International Aerospace Information Opportunity," paper presented at the Strasbourg Conference of Management and Information: From Information Evaluation to Decision, January $15-17,1992$ and published as NASA Technical Memorandum TM-107767, January 1992.

5. Mader, Irene, "The Electronic Information Transmission at the European Space Agency: Use by Industry," paper presented at the Strasbourg Conference on Information Documentation, January 17-19, 1990, and published in Proceedings: Information-Documentation: European Forum, Strasbourg, France, January 1990, by Association Aeronautique et Astronautique de France, Paris, 1990, pps. 153-163.

6. "A Strategic Direction: The NASA Scientific and Technical Information Program," published by the NASA STI Program Office, Washington, DC, 1991.

7. "International Aerospace Information: The NASA Scientific and Technical Information (STI) Program," published by the NASA STI Program Office, Washington, DC, 1991. 
8. "NASA STI Program: Prologue to the Future," published by the NASA STI Program Office, Washington, DC, 1992.

For more information, contact Walter R. Blados, NASA STI Program, Code JTT, Washington, DC 20546, U.S.A.; telephone 1-703-271-5634; telefax 1-703-271-5665/5669; email wblados@sti.nasa.gov 


\begin{tabular}{|c|c|c|c|c|}
\hline \multicolumn{3}{|c|}{ REPORT DOCUMENTATION PAGE } & \multicolumn{2}{|r|}{$\begin{array}{l}\text { Form Approved } \\
\text { OMB NO } 0704-0188\end{array}$} \\
\hline \multicolumn{5}{|c|}{ 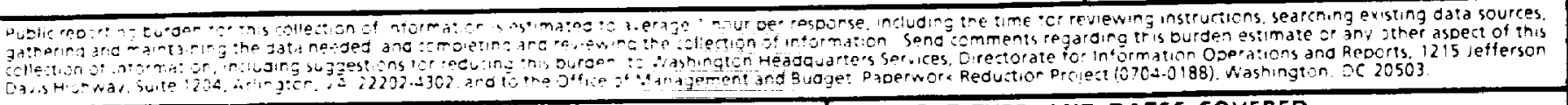 } \\
\hline \multicolumn{2}{|c|}{ 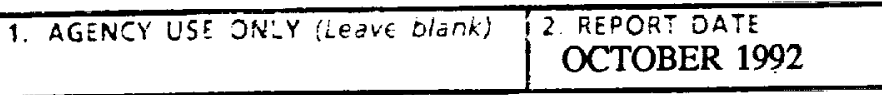 } & \multicolumn{3}{|c|}{ 3. REPORT TYPE AND DATES COVERED } \\
\hline \multicolumn{3}{|c|}{$\begin{array}{l}\text { 4. TITLE ANE SUETITLE } \\
\text { AN INTERNATIONAL AEROSPACE SYSTEM: A COOPERATTVE } \\
\text { OPPORTUNITY }\end{array}$} & \multicolumn{2}{|c|}{ 5. FUHDING NUMBERS } \\
\hline \multicolumn{5}{|c|}{ GLADYS A. COTIER, WALTER R. BLADOS } \\
\hline \multicolumn{3}{|c|}{$\begin{array}{l}\text { 7. PERFOFMING ORGANIZATION WANE(S) AND LDURESS(ES) } \\
\text { NATIONAL AERONAUTICS AND SPACE ADMINISTRATION } \\
\text { WASHINGTON, DC } 20006\end{array}$} & $\begin{array}{l}\text { 8. PERF } \\
\text { REPO } \\
\text { NA }\end{array}$ & $\begin{array}{l}\text { ORMING ORGANIZATION } \\
\text { RT NUMEER } \\
\text { SA TM-108171 }\end{array}$ \\
\hline \multicolumn{3}{|c|}{ 9. SPONSOFIIV G MONITORILE AGERICY NAMELE, AND ADDRESS(ES) } & \multicolumn{2}{|c|}{$\begin{array}{l}\text { 10. SPONSORING MONITORING } \\
\text { AGENCY REPORT NUMBER }\end{array}$} \\
\hline \multicolumn{5}{|l|}{ 11. SUPPLEMENTARY NOTES } \\
\hline \multicolumn{3}{|c|}{$\begin{array}{l}\text { 120. DISTRIEUTION AVAILABILITY STATEMENT } \\
\text { UNCLASSIFIED - UNLIMITED } \\
\text { SUBJECT CATEGORY } 82\end{array}$} & \multicolumn{2}{|c|}{ 12b. DISTRIBUTION CODE } \\
\hline \multirow{2}{*}{\multicolumn{5}{|c|}{$\begin{array}{l}\text { 13. ABSTRACT (Maximum 200 words) } \\
\text { Scientific and technical information (STT) is a valuable resource which represents the results of large investments in } \\
\text { research and development (R\&D), and the expertise of a nation. NASA and its predecessor organizations have } \\
\text { developed and managed the preeminent aerospace information system. We see information and information systems } \\
\text { changing and becoming more international in scope. In Europe, consistent with joint R\&D programs and a view toward } \\
\text { a united Europe, we have seen the emergence of a European Aerospace Database concept. In addition, the development } \\
\text { of aeronautics and astronautics in individual nations are also lead to initiatives for national aerospace databases. } \\
\text { Considering recent technological developments in information science and technology, as well as the reality of scarce } \\
\text { resources in all nations, it is time to reconsider the mutually beneficial possibilities offered by cooperation and } \\
\text { international resource sharing. This paper raises for consideration new possibilities offered by cooperation unification of } \\
\text { te various aerospace database efforts toward a cooperative intemational aerospace database initiative which can optimize } \\
\text { the costbenefit equation for all participants. }\end{array}$}} \\
\hline & & & & \\
\hline \multirow{2}{*}{\multicolumn{4}{|c|}{$\begin{array}{l}\text { 14. SUBIEC TERMS } \\
\text { SCIENTIFIC AND TECHNICAL INFORMATION, RESEARCH DEVELOPMENT, } \\
\text { AEROSPACE INFORMATION, INTERNATIONAL PROGRAMS, AEROSPACE } \\
\text { DATABASE, INFORMATION SCIENCE }\end{array}$}} & $\begin{array}{l}\text { 15. NUMBER OF PAGES } \\
14\end{array}$ \\
\hline & & & & $\begin{array}{r}\text { 16. PRICE CODE } \\
\text { A01 }\end{array}$ \\
\hline $\begin{array}{l}\text { 17. SECURITY CLASSIFICATION } \\
\text { OF REPORT } \\
\text { UNCLASSIFIED }\end{array}$ & $\begin{array}{l}\text { 18. SECURITY CLASSIFICATION } \\
\text { OF THIS PAGE } \\
\text { UNCLASSIFIED }\end{array}$ & $\begin{array}{l}\text { 19. SECURIT } \\
\text { OF ABS } \\
U\end{array}$ & $\begin{array}{l}\text { ICATION } \\
\text { FIED }\end{array}$ & $\begin{array}{l}\text { 20. LIMITATION OF ABSTRACT } \\
\text { UL }\end{array}$ \\
\hline
\end{tabular}

